\title{
Cloning and Expression of a Mutant Methylmalonyl Coenzyme A Mutase with Altered Cobalamin Affinity That Causes mut ${ }^{-}$Methylmalonic Aciduria
}

\author{
Ana María Crane, Ruud Jansen, Elizabeth R. Andrews, and Fred D. Ledley \\ Howard Hughes Medical Institute, Departments of Cell Biology and Pediatrics, Baylor College of Medicine, Houston, Texas 77030
}

\begin{abstract}
Distinct genotypic and phenotypic forms of methylmalonyl CoA mutase (MCM) apoenzyme deficiency can be delineated by biochemical analysis of mutant fibroblasts. One form, designated mut $^{-}$, expresses a phenotype in which residual enzyme activity is evident in cultured cells exposed to high concentrations of hydroxycobalamin. We describe cloning of an MCM cDNA from cells exhibiting a mut ${ }^{-}$phenotype and characterization of the mutant gene product overexpressed in primary $m u t^{\circ}$ human fibroblasts and Saccharomyces cerevisiae. Three novel base changes were observed. Recombinant clones containing one of these base changes (G717V) express four characteristics of the mut $^{-}$phenotype: failure to constitute $\left[{ }^{14} \mathrm{Clpropionate}\right.$ incorporation activity in fibroblasts assayed under basal cell culture conditions, constitution of $\left[{ }^{14} \mathrm{C}\right]$ propionate incorporation activity in fibroblasts stimulated with 0.1-1.0 $\mu \mathrm{g} / \mathrm{ml}$ hydroxycobalamin, interallelic complementation with alleles bearing an R93H mutation, and an apparent $K_{\mathrm{m}}$ (adenosylcobalamin) 1,000-fold higher than normal. These results demonstrate that the G717V mutation produces the mut ${ }^{-}$phenotype and localizes determinants for adenosylcobalamin binding near the carboxyl terminus of MCM. (J. Clin. Invest. 1992. 89:385-391.) Key words: inborn errors of metabolism • organic acids • adenosylcobalamin • molecular cloning • Saccharomyces cerevisiae
\end{abstract}

\section{Introduction}

Methylmalonic aciduria (MMA) ${ }^{1}$ represents a set of inborn errors of metabolism that result from inadequate function of the enzyme L-methylmalonyl CoA mutase (MCM, EC 5.4.99.2). This enzyme catalyzes isomerization of L-methylmalonyl CoA to succinyl CoA in the pathway by which propionate or propionyl $\mathrm{CoA}$ is metabolized via methylmalonyl $\mathrm{CoA}$ to Kreb's cycle intermediates (1). The MCM holoenzyme is a homodimer that contains $1 \mathrm{~mol}$ of an adenosylcobalamin cofactor for each mole of subunit (2). Distinct genotypic forms of MMA are caused by defects in the MCM apoenzyme (designated mut MMA; McKusick number 251000; reference 3) or defects in enzymes required for providing the adenosylcobala-

R. Jansen's present address is Laboratorium coor Moleculaire Biologie, Centraal Diergeneeskundit Instituut, Edelhertweg 15, Netherlands. Address correspondence to F. D. Ledley, Howard Hughes Medical Institute, Department of Cell Biology, Baylor College of Medicine, Houston, TX 77030.

Received for publication 14 August 1991 and in revised form 9 October 1991.

1. Abbreviations used in this paper: $\mathrm{MCM}$, methylmalonyl CoA mutase; MMA, methylmalonic aciduria; PCR, polymerase chain reaction.

J. Clin. Invest.

(c) The American Society for Clinical Investigation, Inc.

0021-9738/92/02/0385/07 \$2.00

Volume 89, February 1992, 385-391 min cofactor (designated cbl MMA; McKusick numbers 251100 and 251110; reference 3). Two distinct phenotypic forms of mut MMA can be delineated by biochemical analysis of fibroblasts from patients with MMA: $m u t^{\circ}$, in which fibroblasts exhibit no $\left[{ }^{14} \mathrm{C}\right]$ propionate incorporation under any conditions or detectable MCM apoenzyme activity in vitro, and $m u t^{-}$, in which fibroblasts exhibit $\left[{ }^{14} \mathrm{C}\right]$ propionate incorporation when stimulated by high concentrations of hydroxycobalamin (4-7). This biochemical variation is thought to underlie the varied clinical expressions of MCM deficiency, which range from fulminant neonatal acidosis, multiorgan failure, and death (8) to benign, persistent MMA without any corresponding clinical or developmental abnormalities (9).

Additional classes of mut MMA have recently been delineated by somatic cell complementation studies with $m u t^{\circ}$ WG1130 fibroblasts (10). Somatic cell fusions between WG1130 and most mut $^{-}$fibroblasts restore $\left[{ }^{14} \mathrm{C}\right]$ propionate incorporation, apparently by interallelic complementation, whereas fusions between WG1 130 and most $m u t^{\circ}$ fibroblasts did not complement $\left[{ }^{14} \mathrm{C}\right]$ propionate incorporation.

We have reported cloning of the normal human MCM cDNA, which comprises 2,798 bases and encodes a propeptide of 750 amino acids $(83,007 \mathrm{D})$ with a 32-amino acid mitochondrial targeting sequence and a 718-amino acid mature apoenzyme $(11,12)$. DNA-mediated gene transfer of this clone into primary $m u t^{\circ}$ fibroblasts restores $\left[{ }^{14} \mathrm{C}\right]$ propionate incorporation to normal levels during the transient phase of recombinant gene expression after electroporation (13), confirming that defects at this gene locus are responsible for the mut genotype. The recombinant MCM apoenzyme has been expressed at high levels in Saccharomyces cerevisiae for biochemical analysis and has been shown to exhibit kinetic parameters indistinguishable from the native enzyme (Andrews, E., R. Jansen, A. M. Crane, M. F. Wilkemeyer, D. McDonnell, and F. D. Ledley, unpublished data). Of particular relevance to the present experiments is the fact that $S$. cerevisiae does not have endogenous MCM (14) and does not produce adenosylcobalamin, so that the recombinant MCM produced in this organism is entirely apoenzyme.

Several mutations have been identified in human MCM $(10,15,16)$, including two nonsense mutations (W105R and A378E) that give rise to a classic $m u t^{\circ}$ phenotype (16) and a mutation $(\mathrm{R} 93 \mathrm{H})$ that exhibits interallelic complementation (10) with mut $^{-}$fibroblasts. We describe here the cloning, sequencing, and expression of an MCM mutation expressing the mut $^{-}$phenotype and the characterization of the activity of the recombinant gene product expressed in fibroblasts and $S$. cerevisiae.

\section{Methods}

Fibroblasts from patients with mut MMA. The DS79 fibroblasts were provided by Dr. David Valle (Johns Hopkins University, Baltimore, MD) and were previously shown to exhibit a mut $^{-}$phenotype (7). 
GM1673 fibroblasts were obtained from the National Institute of General Medical Sciences (Bethesda, MD) Mutant Cell Repository and were previously shown to express a $m u t^{\circ}$ phenotype with low levels of MCM mRNA (7). MAS and WG1130 are $m u t^{\circ}$ cell lines, the mutations of which have been described previously $(10,16)$.

Cloning and sequencing of $M C M C D N A$. Total RNA was prepared from confluent fibroblasts, and cDNA was synthesized and amplified by polymerase chain reaction (PCR; Fig. 1) as described previously (16). First-strand cDNA was generated from oligonucleotide 33 in the $3^{\prime}$ untranslated region of the cDNA and used as a template for two PCR reactions between oligonucleotides 53 and 28 and between oligonucleotides 23 and 21 . The products of the $5^{\prime}$ reaction were cloned into the $\mathrm{ClaI} / \mathrm{KpnI}$ sites of pGEM7zf(+) using the ClaI site within oligonucleotide 53 and the internal KpnI site at base 720 . The products of the $3^{\prime}$ reaction were cloned into the $\mathrm{KpnI} / \mathrm{BamHI}$ sites of pGEM7zf(+) using the internal KpnI and BclI sites. Double-stranded dideoxy sequencing was performed using the T7- (Q5011, Promega Corp., Madison, WI), SP6- (Q5121, Promega), or MCM-specific primers (Fig. 1). Clonal isolates were sequenced and compared with the sequence from a pool of 15 independent clones to confirm the authenticity of sequence variations. Oligonucleotide sequences are in reference 16.

DNA-mediated gene transfer and assay of $\left[{ }^{14} \mathrm{C}\right]$ propionate incorporation in fibroblasts. An expression vector was constructed using the normal human MCM cDNA (pCMV-hMCM) in the plasmid pNAssCMV $(17,18)$, the cytomegalovirus immediate early promoter, the SV40 late viral protein splice donor and acceptor signals, and the SV40 polyadenylation sequences (Fig. $3 \mathrm{~A}$, clone $\mathrm{F}$ ). Mutant clones were constructed by substituting fragments from the PCR-generated cDNA clones into the normal vector (Fig. $3 \mathrm{~A}$ ). A BamHI/Nsil fragment containing $\mathrm{H} 532 \mathrm{R}$ (base 1,671 ) was replaced in a subclone containing the $5^{\prime}$ end of the normal MCM gene (Fig. 3 A, clone 1). A Nsil/EcoRI fragment containing V671I (base 2,087) and G717V (base $2,226)$ was combined with fragments from the normal hMCM expression vector (Fig. $3 \mathrm{~A}$, clone 2). Normal sequences corresponding to V671I were restored by replacing a normal Nsil/AocI fragment, and normal sequences corresponding to $\mathrm{G} 717 \mathrm{~V}$ were restored by replacing a normal AocI/SalI fragment. Full-length clones were reconstituted by three-part ligation from $5^{\prime}$ NotI/Nsil and $3^{\prime}$ Nsil/Sall fragments. All

\section{A. REVERSE TRANSCRIPTION}

mRNA

\section{B. POLYMERASE CHAIN REACTION}

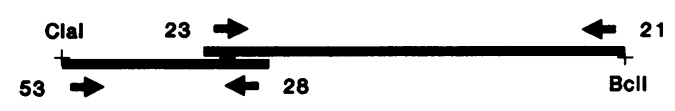

\section{SEQUENCING}

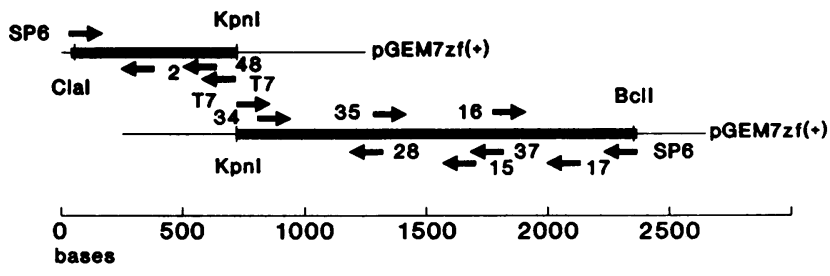

Figure 1. Scheme for cloning and sequencing MCM cDNA. Firststrand cDNA was synthesized with oligonucleotide $33(A)$. This material was added to two PCR reactions that amplify the $5^{\prime}$ and the $3^{\prime}$ ends of the cDNA, respectively $(B)$. The PCR products were subcloned into the ClaI/KpnI or KpnI/BamHI sites of the vector pGEM7zf(+) and sequenced using the SP6 or T7 promoter primers or oligonucleotides complementary to the MCM sequence as indicated $(C)$. The oligonucleotide sequences have been published previously (21). subcloned segments were sequenced to confirm the absence of artifactual sequence changes, and all gene expression experiments were performed with two independent subclones.

The clones were introduced via electroporation (19) into GM1673 cells, which express low amounts of MCM mRNA and no significant $\left[{ }^{14} \mathrm{C}\right]$ propionate incorporation under any conditions $(7,13)$. Electroporation was performed using a Gene Pulser (Bio-Rad Laboratories, Richmond, CA) after a 5-min incubation of $0.3 \mathrm{ml}$ of cells (density of $1.2 \times 10^{7} / \mathrm{ml}$ ) with $10-20 \mu \mathrm{g} \mathrm{DNA}$, voltage pulses of $260 \mathrm{~V}$, and capacitance of $960 \mu \mathrm{F}$. MCM activity was assayed $2 \mathrm{~d}$ after electroporation by $\left[{ }^{14} \mathrm{C}\right]$ propionate incorporation $(7,13,20,21)$.

Incorporation of $\left[{ }^{14} \mathrm{C}\right]$ propionate into TCA-precipitable material is dependent on MCM holoenzyme activity and provides a sensitive measure of MCM holoenzyme activity. $\left[{ }^{3} \mathrm{H}\right]$ Leucine incorporation was measured to normalize for cell number and constitutive protein synthesis. The results are expressed as the mean nanomoles propionate per micromole leucine incorporated in triplicate samples. Cobalamin responsiveness of mut $^{-}$cells was assayed by measuring $\left[{ }^{14} \mathrm{C}\right]$ propionate incorporation in the presence of $1.0 \mu \mathrm{g} / \mathrm{ml}$ hydroxycobalamin. Signifcant propionate incorporation is determined from the mean and standard deviation compared with GM1673 controls.

Expression and enzyme assays in S. cerevisiae. The vector pYEPVhMCM for expression of human MCM in $S$. cerevisiae will be described elsewhere (Andrews, E., R. Jansen, A. M. Crane, M. F. Wilkemeyer, D. McDonnell, and F. R. Ledley, unpublished data). This clone contains the human MCM open reading frame with truncated $5^{\prime}$ and $3^{\prime}$ untranslated regions, the CUP1p promoter, $2 \mu$ origin of replication, and TRP-1 gene for tryptophan selection (22) (Fig. $5 \mathrm{~A}$ ). Sequence fragments containing all three sequence variations or only $\mathrm{G} 717 \mathrm{~V}$ were substituted into this vector on a KpnI/EcoRI segment by three-part ligation of the mutant $\mathrm{KpnI} / \mathrm{EcoRI}$ fragment with EcoRI/ClaI and $\mathrm{KpnI} / \mathrm{ClaI}$ fragments from the normal clone. The clones were introduced into the proteinase-deficient $S$. cerevisiae strain BJ3505 (Trp1 ${ }^{-}$, $\mathrm{Ura3}^{-}$), and expression of the recombinant gene was induced with 100 $\mu \mathrm{M} \mathrm{CuSO}_{4}$ when cultures reached an $\mathrm{OD}_{600}$ of 0.5 . The cells were harvested $4 \mathrm{~h}$ after induction by centrifugation; lysed using Glassperlen $^{\mathrm{TM}}$ (B. Braun Melsungen, Melsungen, Germany) $(0.45-0.5 \mathrm{~mm})$ in $28 \mathrm{mM} \mathrm{NaPO}_{4}$, pH 7.0, 5 mM EDTA; and cleared of particulate matter by centrifugation.

MCM activity was measured in vitro using the potassium permanganate/perchloric acid method (23-25). Each reaction contained 50$200 \mu \mathrm{g}$ crude extract, $100 \mathrm{mM}$ Tris- $\mathrm{PO}_{4}, \mathrm{pH} \mathrm{7.5,} \mathrm{0.5-2} \mathrm{mM} \mathrm{D/L-meth-}$ ylmalonyl CoA (Sigma Chemical Co., St. Louis, MO), 160,000 dpm D/L- $\left[{ }^{14} \mathrm{C}\right]$ methylmalonyl CoA $(56 \mathrm{mCi} / \mathrm{mmol}$, Amersham Corp., Arlington Heights, IL), and 0-1.0 mM adenosylcobalamin in a volume of $300 \mu \mathrm{l}$. The reaction was incubated in the dark for $20 \mathrm{~min}$ at $30^{\circ} \mathrm{C}$ and stopped by adding $100 \mu \mathrm{l} 2 \mathrm{M}$ perchloric acid and boiling. The total protein content was determined using a protein assay (BioRad Laboratories). Each experiment was performed in triplicate, and the results are expressed as nanomoles succinate formed/milligram protein per hour.

\section{Results}

Characteristics of DS79 (mut ${ }^{-}$) fibroblasts. Diagnostic studies of DS79 fibroblasts have shown that these cells belong to the mut complementation group. Studies in our laboratory confirm that these cells exhibit no detectable apoenzyme in vitro under standard assay conditions and no significant $\left[{ }^{14} \mathrm{C}\right]-$ propionate incorporation under basal culture conditions. The addition of hydroxycobalamin to the culture at concentrations of $0.1-1.0 \mu \mathrm{g} / \mathrm{ml} \mathrm{stimulated}\left[{ }^{14} \mathrm{C}\right]$ propionate incorporation (7). The diagnosis of mut MMA was confirmed by DNA-mediated gene transfer, which restored $\left[{ }^{14} \mathrm{C}\right]$ propionate incorporation (13). Thus, we conclude that these fibroblasts exhibit a mut $^{-}$ phenotype analogous to the one originally described by Willard and Rosenberg (4-6). 
Identification of mutations in DS79. Three differences were identified between the sequence of DS79 and the consensus sequence: H532R $(\mathrm{a} \rightarrow \mathrm{g}$, base 1,671), V671I $(\mathrm{g} \rightarrow \mathrm{a}$, base 2,087), and G717V ( $\rightarrow \mathrm{t}$, base 2,226) (Fig. 2). All three novel sequences were uniformly present in a mixture of $15 \mathrm{cDNA}$ clones, suggesting that these sequences were not PCR artifacts. Thus, this patient is homozygous for all three novel sequences or is a compound heterozygote in which the heterologous allele is not represented in the cDNA clones (15).

To confirm that these sequence variations were responsible for the $\mathrm{mut}^{-}$phenotype, an expression vector that contained all three changes was constructed (Fig. 3 A, clone A). This clone was not capable of inducing $\left[{ }^{14} \mathrm{C}\right]$ propionate incorporation in $m u t^{\circ} \mathrm{GM} 1673$ fibroblasts assayed under basal conditions, but activity was stimulated when $1 \mu \mathrm{g} / \mathrm{ml}$ hydroxycobalamin was added to the culture media (Fig. $3 B$, lane $A$ ). This stimulation is quantitatively similar to the $\left[{ }^{14} \mathrm{C}\right]$ propionate incorporation observed in the parental DS79 cells without electroporation (Fig. $3 C, B L A N K$ ) or after electroporation with the vector alone (Fig. $3 C, C M V$ ). These data demonstrate that the MCM cDNA from the DS79 fibroblasts expressed the phenotype of the parental cells.

Expression constructs were made with different permutations of the three potential mutations to determine which amino acid change was responsible for the pathological phenotype. Clones containing only $\mathrm{H} 532 \mathrm{R}$ (Fig. 3 A, clone B) or only V671I (Fig. $3 A$, clone $D$ ) induced $\left[{ }^{14} C\right]$ propionate incorporation (Fig. $3 B$, lanes $B$ and $D$ ) equivalent to that of a normal MCM clone (Fig. $3 B$, lane $F$ ). Clones containing both V671I and G717V (Fig. $3 \mathrm{~A}$, clone $C$ ) or only G717V (Fig. $3 \mathrm{~A}$, clone $E$ ) failed to constitute $\left[{ }^{14} \mathrm{C}\right]$ propionate incorporation under basal conditions, but incorporation was evident in cells treated with $1 \mu \mathrm{g} / \mathrm{ml}$ hydroxycobalamin (Fig. $3 B$, lanes $C$ and $E$ ). Thus, G717V alone was responsible for the impaired MCM activity in DS79 cDNA clones.

Interallelic complementation between $G 717 \mathrm{~V}$ and $\mathrm{R} 93 \mathrm{H}$ mutations. To test whether the G717V mutation exhibited the complete phenotype of the parental DS79 fibroblasts, we investigated whether clones with $G 717 \mathrm{~V}$ would complement the R93H mutation (10). It has been shown previously that DNAmediated gene transfer of clones with $\mathrm{R} 93 \mathrm{H}$ into the $m u t^{\circ}$ fibroblasts GM1673 (low mRNA phenotype) or MAS (heterozygous for W105R and A378E mutations) does not restore $\left[{ }^{14} \mathrm{C}\right]-$ propionate incorporation, whereas DNA-mediated gene transfer of the same clone into the DS79 fibroblasts increased $\left[{ }^{14} \mathrm{C}\right]$ propionate incorporation (10). To replicate this phenomenon, equal concentrations of plasmids with the $G 717 \mathrm{~V}, \mathrm{R} 93 \mathrm{H}$, $\mathrm{W} 105 \mathrm{R}$, or $\mathrm{A} 378 \mathrm{E}$ mutations were electroporated into GM1673 fibroblasts in various combinations (Fig. $4 \mathrm{~A}$ ) or into DS79 (Fig. 4 B). $\left[{ }^{14} \mathrm{C}\right]$ Propionate incorporation in GM1673 fibroblasts was not stimulated by vector alone, W105R, A378E, R93H, or G717V. Combinations of G717V + W105R or $\mathrm{G} 717 \mathrm{~V}+\mathrm{A} 378 \mathrm{E}$ similarly failed to constitute $\left[{ }^{14} \mathrm{C}\right]-$ propionate incorporation, as did combinations of $\mathrm{R} 93 \mathrm{H}$ $+\mathrm{W} 105 \mathrm{R}$ or $\mathrm{R} 93 \mathrm{H}+\mathrm{A} 378 \mathrm{E}$. In contrast, cells electroporated with G717V + R93H exhibited increased $\left[{ }^{14} \mathrm{C}\right]$ propionate incorporation equivalent to that attained by transfer of $\mathrm{R} 93 \mathrm{H}$ clones into the parental DS79 fibroblasts (Fig. $4 \mathrm{~B}$ ). These experiments demonstrate selective interallelic complementation between the G717V and R93H mutations.

Characteristics of the mutant gene product. Segments of the mutant cDNA bearing all three novel sequences or the G717V mutation alone were substituted for normal sequences in the expression vector YEPV-MCM (Fig. $5 \mathrm{~A}$ ) and introduced into
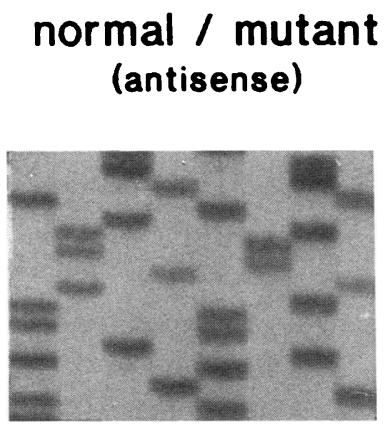

\section{normal / mutant (antisense)}

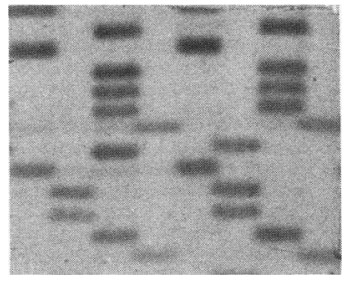

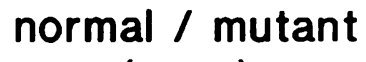

(sense)

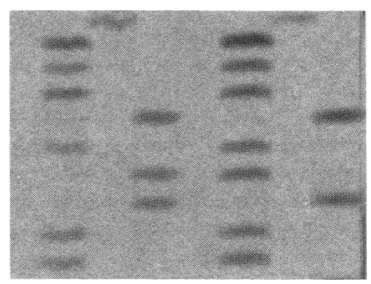

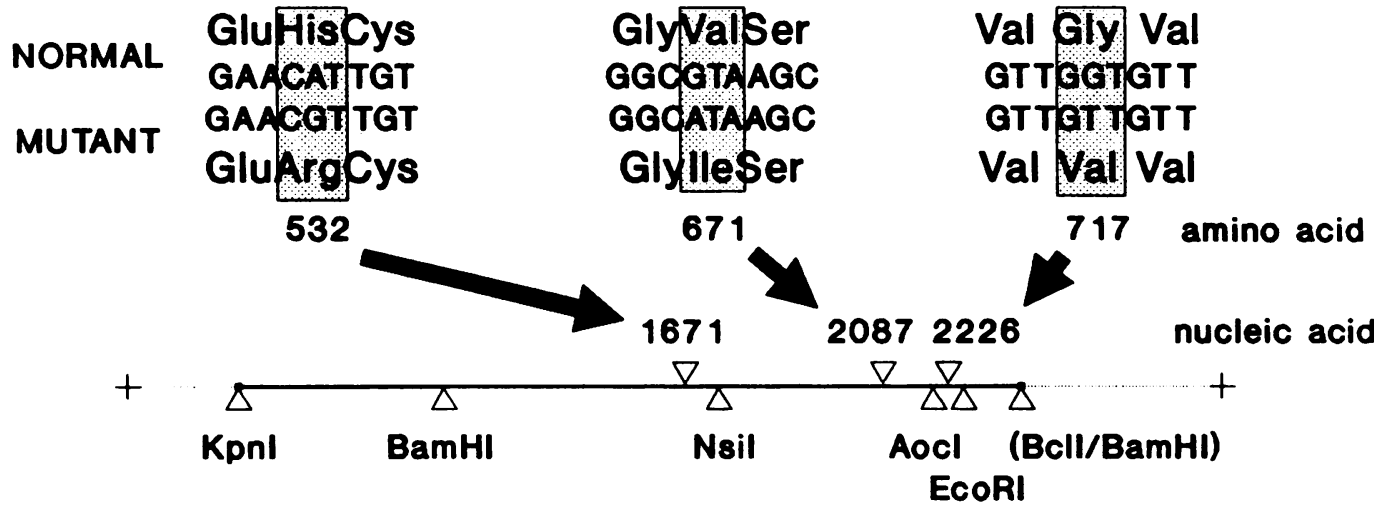

Figure 2. Novel sequences identified in DS79 fibroblasts. Three differences were observed between the MCM cDNA sequences from DS79 and the normal (consensus) sequence of human MCM. The changes in nucleic acids and amino acids are shown. The order of sequencing lanes is $\mathrm{A}$, T, C, G. 


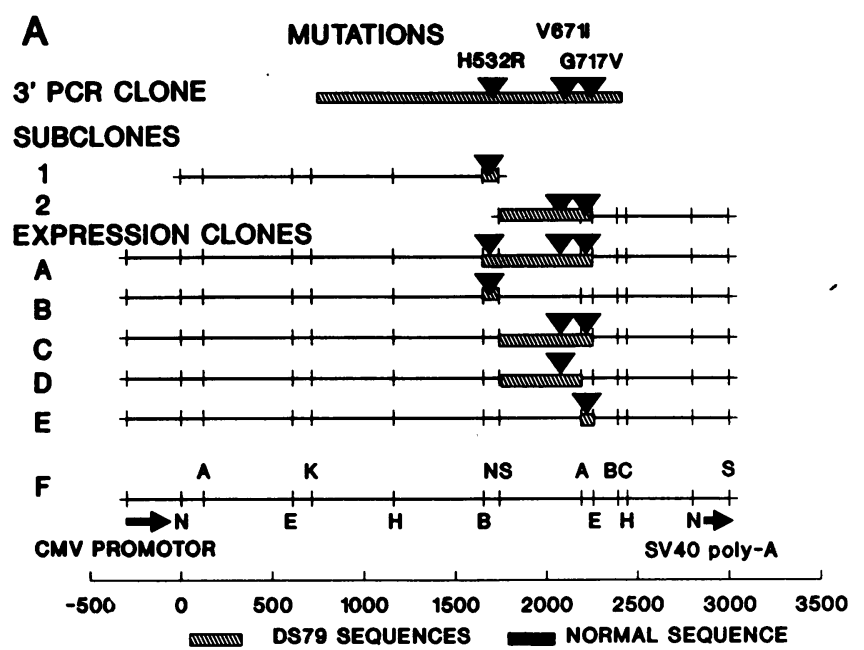

B

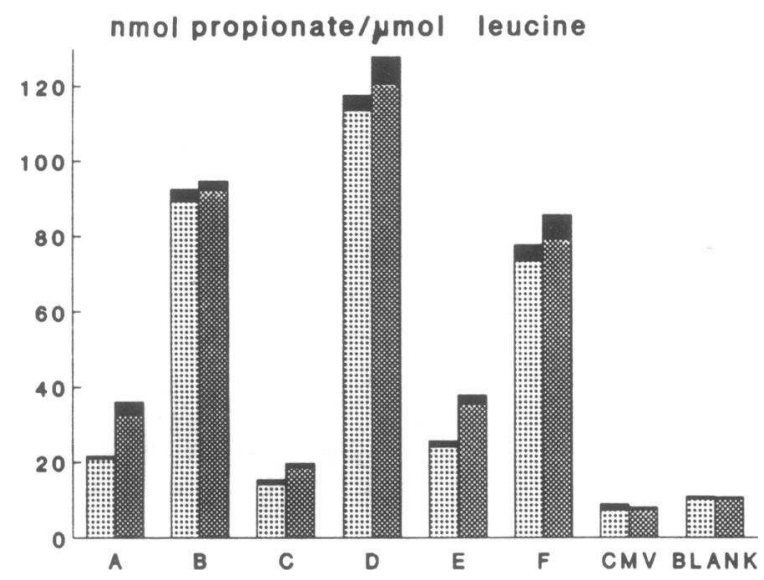

C

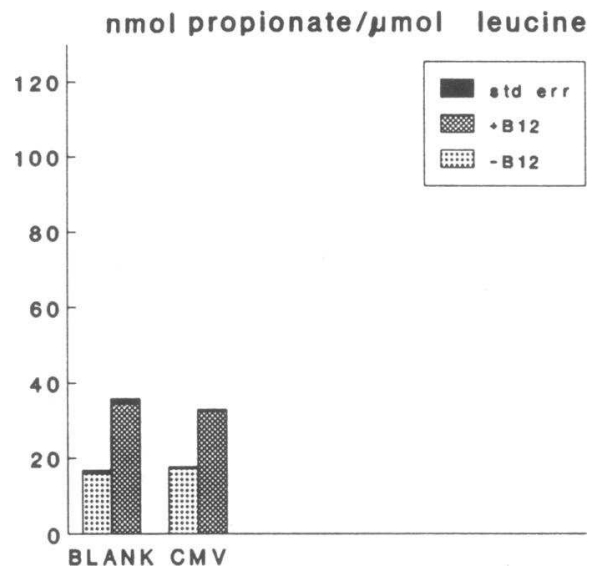

Figure 3. Expression of cDNA clones containing novel sequences and identification of the pathogenic mutation. $(A)$ Construction of expression vectors. Segments of the $3^{\prime}$ PCR clone were combined with normal sequences in the vector pGEM5 (clones 1 and 2) and then substituted into the normal MCM expression vector $\mathrm{pCMV}$ hMCM (clone F). Each construct contains different permutations of the novel sequences observed in DS79, which are indicated by inverted trian-

gles. (B) Expression of mutant clones in primary mut fibroblasts. The expression vectors containing various combinations of base changes illustrated in $A$ (clones $A-F$ ) were electroporated into a primary mut, GM1673 fibroblasts. $\left[{ }^{14} \mathrm{C}\right]$ Propionate incorporation was assayed (in triplicate) in the absence or presence of $1 \mu \mathrm{g} / \mathrm{ml} \mathrm{B} 12$ (hydroxycobalamin). Lanes $A-F$ correspond to cells electroporated with the corresponding clone illustrated in $A$. BLANK, nonelectroporated cells, $C M V$, cells transformed with vector alone as a control. (C) Activity of the parental mut ${ }^{-}$ fibroblasts DS79. $\left[{ }^{14} \mathrm{C}\right]$ Propionate incorporation is shown in the absence or presence of $1 \mu \mathrm{g} / \mathrm{ml} \mathrm{B} 12$ (hydroxycobalamin). BLANK, nonelectroporated cells; $C M V$, cells transformed with vector alone as a control.

$S$. cerevisiae. No MCM enzyme activity was detected in extracts containing the mutant enzyme in the presence of concentrations of adenosylcobalamin $<10 \mu \mathrm{M}$, which stimulated maximal activity of the normal enzyme. MCM activity was detected in extracts containing the mutant enzymes in the presence of higher concentrations of adenosylcobalamin ( $1 \mathrm{mM})$. The mutant enzyme exhibited a similar dependence on substrate concentration. Maximal activity in extracts that con-
A

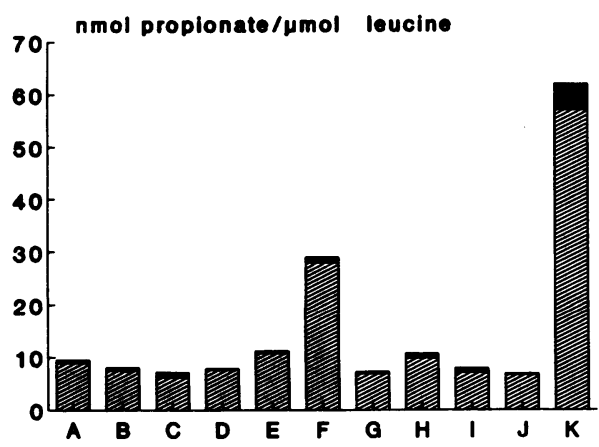

B

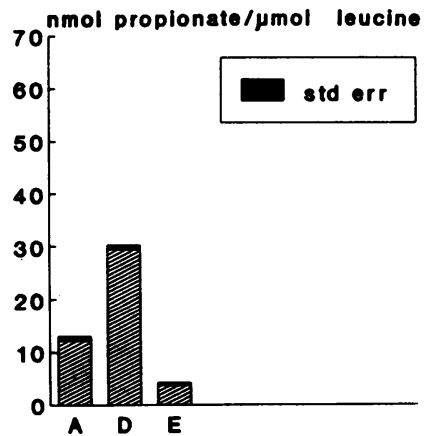

Figure 4. Interallelic complementation between clones with the G717V and R93H mutations. $(A)$ Cotransformation of $m u t^{\circ}$ fibroblasts with mutant cDNA clones. Mutant MCM clones containing G717V, R93H, W105R, or A378E were electroporated into $m u t^{\circ}, \mathrm{GM} 1673$ fibroblasts alone, or in combinations. All experiments were performed in the absence of added cofactor. $A, \mathrm{CMV}$ vector alone; $B, \mathrm{~W} 105 \mathrm{R} ; C$, A378E; $D, \mathrm{R} 93 \mathrm{H} ; E, \mathrm{G} 717 \mathrm{~V} ; F, \mathrm{G} 717 \mathrm{~V}+\mathrm{R} 93 \mathrm{H} ; G$, G717V + W105R; H, G717V + A378E; I, R93H + W105R; J, R93H + A378E; $K$, normal human MCM. (B) Mutant clones were electroporated into the mut $^{-}$, DS79 fibroblasts as a control. Letter designations are the same as in $A$. 
A
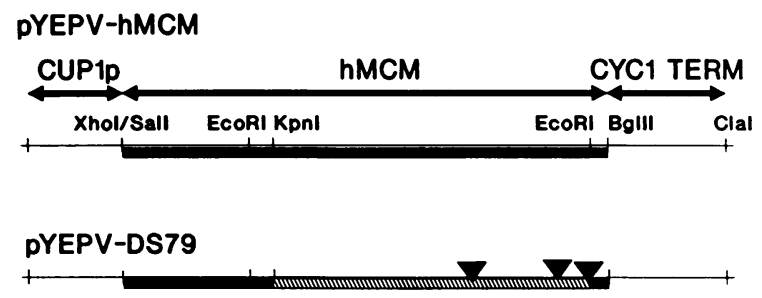

PYEPV-DS79(Val)

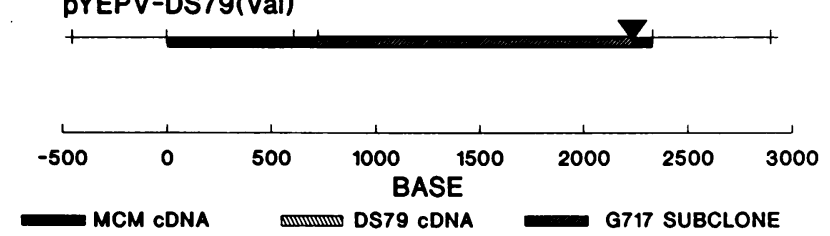

B

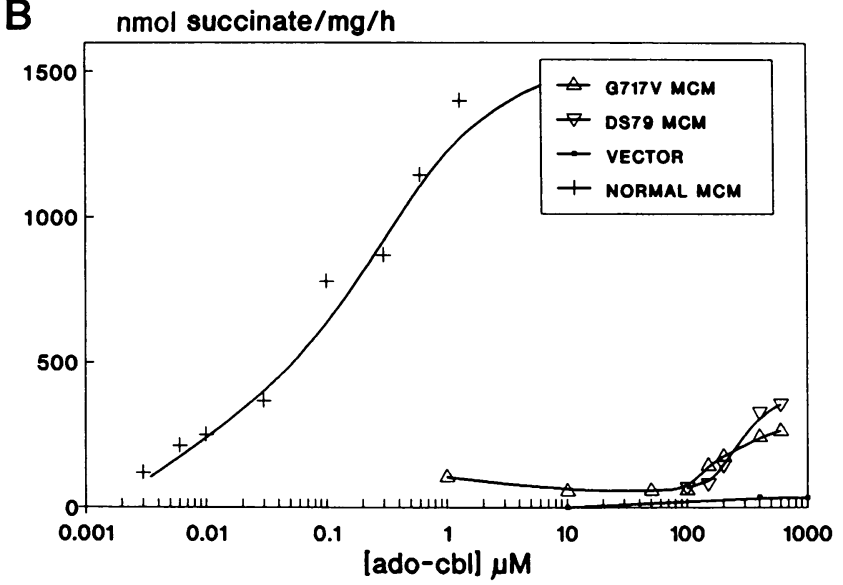

Figure 5. Expression of mutant cDNA in $S$. cerevisiae. $(A)$ Vector for expression of mutant cDNA in $S$. cerevisiae. Normal hMCM has been expressed in the YEPV vector containing the CUP promoter. Segments of the 3' PCR clones from fibroblasts DS79 (Fig. 3 A, clone $A$ ) containing all three sequence variations or segments containing only the G717V mutation (Fig. $3 \mathrm{~A}$, clone $E$ ) were substituted into the YEPV-hMCM vector. The clone containing all three sequence variations ( $Y E P V-D S 79)$ has a reading frame identical to the mRNA of DS79 fibroblasts. The other clone (YEPV-DS79[ $\mathrm{Val}])$ contains only a single deviation from the normal sequence. The position of mutations is indicated by triangles. (B) MCM activity in $S$. cerevisiae expressing normal or mutant human MCM. MCM activity was assayed in vitro as a function of cobalamin concentration. Activity of normal MCM produced in $S$. cerevisiae, MCM containing all three sequence variations (- $\nabla-)$, MCM containing only the G717V mutation $(-\Delta-)$, and YEPV vector alone are shown. Extracts with mutant clones were assayed in the presence of $2 \mathrm{mM}$ methylmalonyl CoA. Extracts with normal clones were assayed in the presence of 0.5 mM methylmalonyl CoA.

tained the mutant enzyme was $<1 \%$ of that observed in extracts containing the normal enzyme (Table I). The apparent $K_{\mathrm{m}}$ (adenosylcobalamin) of the normal recombinant protein (Fig. $5 \mathrm{~B}$ ) is similar to that of native human MCM in crude liver extracts and to data reported by our laboratory previously (26). The apparent $K_{\mathrm{m}}$ values for the cDNA bearing all three sequence changes and the one bearing only the G717V mutation (Fig. $5 B$ ) are consistent with the values reported from studies of primary mut $^{-}$fibroblasts $(4,6)$. These data demonstrate that
Table I. Specific Activity of MCM in Crude Extracts of Liver and S. cerevisiae Expressing Recombinant Human MCM

\begin{tabular}{lrr}
\hline & \multicolumn{2}{c}{$\begin{array}{c}\text { Nanomoles succinate formed/ } \\
\text { mg per hour [Methylmalonyl CoA] }\end{array}$} \\
\cline { 2 - 3 } \multicolumn{1}{c}{ Source } & $0.5 \mathrm{mM}$ & $2 \mathrm{mM}$ \\
\hline Mouse liver & 428 & $\mathrm{NA}$ \\
YEPV & 5 & 7 \\
YEPV + hMCM & 1,238 & 5,121 \\
YEPV + DS79 & 81 & 353 \\
YEPV + DS79(Val) & 120 & 265 \\
\hline
\end{tabular}

Maximal MCM activity was assayed in vitro in the presence of $0.6-$ $1.0 \mathrm{mM}$ adenosylcobalamin. No activity was detectable in the absence of exogenously added cofactor. NA, not assayed.

the G717V mutation affected the adenosylcobalamin-binding function of the apoenzyme.

\section{Discussion}

This report describes a mutation in the MCM cDNA that is responsible for an intermediate defect in enzyme activity. The clone was isolated from fibroblasts that exhibit a mut $^{-}$phenotype in which $\left[{ }^{14} \mathrm{C}\right]$ propionate metabolism is essentially undetectable under basal conditions, but can be stimulated by the addition of excess hydroxycobalamin. Previous work by Willard and Rosenberg (4-6) suggested that such cell lines contain an enzyme with an altered $K_{\mathrm{m}}$ for adenosylcobalamin. We found that clones that contain a single mutation, G717V, expressed four unique characteristics of the mut $^{-}$phenotype: (a) failure to constitute $\left[{ }^{14} \mathrm{C}\right]$ propionate incorporation in $m u t^{\circ}$ cells under basal culture conditions, $(b)$ the ability to constitute $\left[{ }^{14} \mathrm{C}\right]$ propionate incorporation in $m u t^{\circ}$ cells cultured with $1 \mu \mathrm{g} /$ ml hydroxycobalamin, $(c)$ interallelic complementation with alleles bearing the $\mathrm{R} 93 \mathrm{H}$ mutation, and $(d)$ an apparent $K_{\mathrm{m}}$ (adenosylcobalamin) 1,000-fold higher than normal.

We previously identified several mutations that cause $m u t^{\circ}$ phenotypes in which enzyme activity is completely eliminated (27). One is an amber mutation that terminates normal translation at codon 17 and leads to the translation of truncated gene products from internal AUG codons (15), one introduces a hydrophilic residue in a sharply hydrophobic region at the center of the protein (16), and one alters an aromatic tryptophan residue to arginine (16). We have also identified a mutation in WG1130 fibroblasts that exhibits interallelic complementation with most $\mathrm{mut}^{-}$fibroblasts but not most $m u t^{\circ}$ fibroblasts (10). Each of these mutations occurs within the amino-terminal portion of the protein, and we have hypothesized that determinants in this region play a critical role in catalytic function.

In contrast, this study identified three positions at which the clones from DS79 differed from the consensus sequence of other clones of normal and $m u t^{\circ}$ cell lines that have been sequenced in our laboratory. Each of these potential mutations is near the carboxy terminus of the protein. One, H532R, is a nonconservative substitution that does not interfere with enzyme activity, suggesting that it occurs in a region of the protein not intimately involved in function. Another, V671I, is highly conservative. The pathogenic mutation is $G 717 \mathrm{~V}$, 


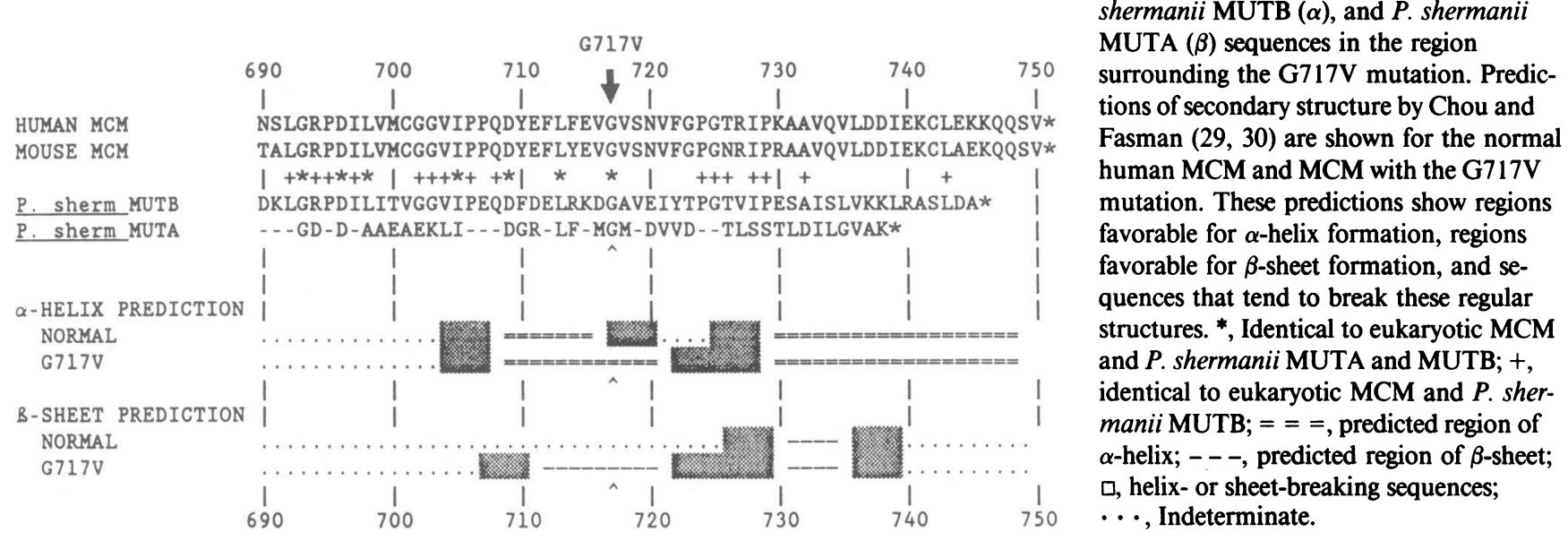

Figure 6. Structural context of the G717V mutation. Optimal sequence alignment is shown for human MCM, mouse MCM, $P$. shermanii MUTB $(\alpha)$, and $P$. shermanii MUTA $(\beta)$ sequences in the region surrounding the G717V mutation. Predictions of secondary structure by Chou and Fasman $(29,30)$ are shown for the normal human MCM and MCM with the G717V mutation. These predictions show regions favorable for $\alpha$-helix formation, regions favorable for $\beta$-sheet formation, and sequences that tend to break these regular structures. *, Identical to eukaryotic MCM and $P$. shermanii MUTA and MUTB; + , identical to eukaryotic MCM and $P$. shermanii $\mathrm{MUTB} ;===$, predicted region of $\alpha$-helix; - - -, predicted region of $\beta$-sheet; $\cdots$, Indeterminate.

which is not conservative because of the critical role glycine residues play in the secondary structure, stabilizing $\beta$-turns and disrupting both regular $\alpha$-helical and $\beta$-sheet structures. ChouFasman predictions of secondary structure $(28,29)$ for the normal and mutant sequences in this region suggest either that the absence of the helix terminating glycine could enable an adjacent $\alpha$-helix to extend further toward the carboxy terminus, or that valine in this position could initiate $\beta$-sheet formation that would not be predicted for the normal protein (Fig. 6).

Homologous MCM genes have been cloned from mouse and from the prokaryote Propionibacterium shermanii. The murine enzyme exhibits $94 \%$ amino acid sequence identity and similar kinetics as human (26). $P$. shermanii MCM is a heterodimer of homologous $\alpha$ (MUTB gene) and $\beta$ (MUTA gene) subunits $(30,31)$. There is a $59 \%$ identity between human MCM and the $P$. shermanii MUTB gene and a $22 \%$ identity between human MCM and the MUTA gene (32). The glycine residue at position 717 is conserved in human, murine, and $P$. shermanii MUTB sequences but not in MUTA (Fig. 6). There is, however, little overall sequence preservation between the eukaryotic and prokaryotic enzymes in the regions immediately surrounding this glycine. There is similarity in flanking regions that could fold together to constitute homologous cobalamin-binding determinants. This pattern of homology predicts that the effect of the G717V mutation may be to disrupt the tertiary assembly of these determinants by introducing additional rotation at the end of a segment of $\alpha$-helix or folding this region deeper into the hydrophobic core of the protein.

The position of this mutation and the pattern of homology between the eukaryotic and prokaryotic enzymes are interesting, considering the interallelic complementation observed between $\mathrm{G} 717 \mathrm{~V}$ and $\mathrm{R} 93 \mathrm{H}$. It has been proposed that this complementation may result from constitution of a single asymmetrical catalytic center composed of cobalamin-binding determinants from clones bearing the R93H mutation with discrete catalytic functions remaining on $\mathrm{mut}^{-}$alleles (10). This is consistent with evidence that the normal enzyme binds $2 \mathrm{~mol}$ of adenosylcobalamin/homodimer (2) and with a model in which the catalytic core is composed of two symmetrical catalytic centers constituted in trans from determinants on opposite subunits. It is interesting that there is no apparent homol- ogy between MUTB and MUTA in the regions surrounding this presumed cobalamin-binding site, given the observation that $P$. shermanii MCM binds only $1 \mathrm{~mol}$ adenosylcobalamin/ heterodimer (Leadlay, P. F., personal communication). A more detailed picture of structure function determinants will arise from knowledge of the tertiary structure of $\operatorname{MCM}(33)$ and additional characterization of natural or site-directed mutants of the eukaryotic or prokaryotic proteins.

\section{Acknowledgments}

The authors thank Dr. David Valle for contributing the DS79 fibroblasts, Amira Elgawly for technical assistance, and Tammy Reid for preparation of this manuscript.

This work was supported by grants HD-24186 and HD-24064 from the National Institutes of Health. F. D. Ledley is an Assistant Investigator of the Howard Hughes Medical Institute.

\section{References}

1. Rosenberg, L. E., and W. A. Fenton. 1989. Disorders of propionate and methylmalonate metabolism. In The Metabolic Basis of Inherited Disease. 6th ed. C. R. Scriver, A. L. Beaudet, W. S. Sly, and D. Valle, editors. McGraw Hill, New York. 822-844.

2. Cannata, J. J., A. Focesi, R. Mazumder, R. C. Warner, and S. Ochoa. 1965. Metabolism of propionic acid in animal tissues. XII. Properties of mammalian methylmalonyl CoA mutase. J. Biol. Chem. 240:3249-3257.

3. McKusick, V. A. 1990. Mendelian Inheritance in Man. 9th ed. Johns Hopkins University Press, Baltimore, MD. 1328-1329.

4. Willard, H. F., and L. E. Rosenberg. 1977. Inherited deficiencies of human methylmalonyl $\mathrm{CoA}$ mutase activity: reduced affinity of mutant apoenzyme for adenosylcobalamin. Biochem. Biophys. Res. Commun. 78:927-934.

5. Willard, H. F., and L. E. Rosenberg. 1979. Inherited deficiencies of methylmalonyl CoA mutase: biochemical and genetic studies in cultured skin fibroblasts. In Methods for the Study of Inborn Errors of Metabolism. R. A. Hommes, editor. Elsevier, New York. 297-311.

6. Willard, H. F., and L. E. Rosenberg. 1980. Inherited methylmalonyl CoA mutase apoenzyme deficiency in human fibroblasts: evidences for allelic heterogeneity, genetic compounds, and codominant expression. J. Clin. Invest. 65:690 698.

7. Ledley, F. D., A. M. Crane, and M. Lumetta. 1990. Heterogeneous alleles and expression of methylmalonyl CoA mutase in mut methylmalonic acidemia. Am. J. Hum. Genet. 46:539-547.

8. Matsui, S. M., M. J. Mahoney, and L. E. Rosenberg. 1983. The natura history of the inherited methylmalonic acidemias. $N$. Engl. J. Med. 308:857-861.

9. Ledley, F. D., H. L. Levy, V. E. Shih, R. Benjamin, and M. J. Mahoney. 1984. Benign methylmalonic aciduria. N. Engl. J. Med. 311:1015-1018. 
10. Raff, M. L., A. M. Crane, R. Jansen, F. D. Ledley, and D. S. Rosenblatt. 1991. Genetic characterization of $m u t$ locus mutation discriminating heterogeneity in $m u t^{\circ}$ and $m u t^{-}$methylmalonic aciduria by interallelic complementation. $J$. Clin. Invest. 87:203-207.

11. Ledley, F. D., M. Lumetta, P. N. Nguyen, J. F. Kolhouse, and R. H. Allen. 1988. Molecular cloning of L-methylmalonyl-CoA mutase: gene transfer and analysis of mut cell lines. Proc. Natl. Acad. Sci. USA. 85:3518-3521.

12. Jansen, R., F. Kalousek, W. A. Fenton, L. E. Rosenberg, and F. D. Ledley. 1989. Cloning of full-length methylmalonyl-CoA mutase from a cDNA library using the polymerase chain reaction. Genomics. 4:198-205.

13. Wilkemeyer, M. F., A. M. Crane, and F. D. Ledley. 1991. Differential diagnosis of $m u t$ and $c b l$ methylmalonic aciduria by DNA-mediated gene transfer in primary fibroblast. J. Clin. Invest. 87:915-918.

14. Ledley, F. D., A. M. Crane, K. T. Klish, and G. S. May. 1991. Is there methylmalonyl CoA mutase in Aspergillus nidulans? Biochem. Biophys. Res. Commun. 177:1076-1081.

15. Ledley, F. D., R. Jansen, S. U. Nham, W. E. Fenton, and L. E. Rosenberg. 1990. Mutation eliminating mitochondrial leader sequence of methylmalonyl CoA mutase causes $m u t^{\circ}$ methylmalonic acidemia. Proc. Natl. Acad. Sci. USA. 87:3147-3150.

16. Jansen, R., and F. D. Ledley. 1990. Heterozygous mutations at the mut locus in fibroblasts with mut methylmalonic acidemia identified by polymerase chain reaction cDNA cloning. Am. J. Hum. Genet. 47:808-814.

17. MacGregor, G., and C. T. Caskey. 1989. Construction of plasmids that express $E$. coli $\beta$-galactosidase in mammalian cells. Nucleic Acids Res. 17:2365.

18. MacGregor, G. R., G. P. Nolan, S. Fiering, and L. A. Herzenberg. 1991. Methods Mol. Biol. 7:217-235.

19. Shigekawa, K., and W. J. Dower. 1988. Electroporation of eukaryotes and prokaryotes: a general approach to the introduction of macromolecules into cells BioTechniques. 6:742-751.

20. Rosenblatt, D. S., B. A. Cooper, A. Pottier, H. Leu-Shing, N. Matiaszuk and K. Grauer. 1984. Altered vitamin B12 metabolism in fibroblasts from a patient with megaloblastic anemia and homocystinuria due to a new defect in methionine biosynthesis. J. Clin. Invest. 74:2149-2156.

21. Willard, H. F., L. M. Ambani, A. C. Hart, M. J. Mahoney, and L. E. Rosenberg. 1976. Rapid prenatal and postnatal detection of inborn errors of propionate, methylmalonate, and cobalamin metabolism: a sensitive assay using cultured cells. Hum. Genet. 34:277-283.

22. McDonnell, D. P., J. W. Pike, D. J. Drutz, T. R. Butt, and B. W. O'Malley. 1989. Reconstitution of the vitamin D-responsive osteocalcin transcription unit in Saccharomyces cerevisiae. Mol. Cell. Biol. 9:3517-3523.

23. Kolhouse, J. F., S. P. Stabler, and R. H. Allen. 1988. L-methylmalonylCoA mutase from human placenta. Methods Enzymol. 166:407-414.

24. Kolhouse, J. F., C. Utley, and R. H. Allen. 1980. Isolation and characterization of methylmalonyl-CoA mutase from human placenta. J. Biol. Chem. 255:2708-2712.

25. Fenton, W. A., A. M. Hack, H. F. Willard, A. Gertler, and L. E. Rosenberg. 1982. Purification and properties of methylmalonyl coenzyme A mutase from human liver. Arch. Biochem. Biophys. 214:815-823.

26. Wilkemeyer, M., A. M. Crane, and F. D. Ledley. 1990. Primary structure and activity of murine methylmalonyl CoA mutase. Biochem. J. 271:449-455.

27. Ledley, F. D. 1990. Perspectives on methylmalonic acidemia resulting from molecular cloning of methylmalonyl CoA mutase. Bioessays. 12:335-340.

28. Chou, P. Y., and G. D. Fasman. 1974. Conformational parameters for amino acids in helical, beta-sheet, and random coil regions calculated from proteins. Biochemistry. 13:211-222.

29. Chou, P. Y., and G. D. Fasman. 1974. Prediction of protein conformation. Biochemistry. 13:222-245.

30. Marsh, N., N. McKie, N. K. Davis, and P. F. Leadlay. 1989. Cloning and structural characterization of the genes coding for adenosylcobalamin-dependent methylmalonyl-CoA mutase from Propionibacterium shermanii. Biochem. J. 260:345-352.

31. Francalanci, F., N. K. Davis, J. Q. Fuller, D. M. Murfitt, and P. F. Leadlay. 1986. The subunit structure of methylmalonyl-CoA mutase from Propionibacterium shermanii. Biochem. J. 236:489-494.

32. Leadlay, P. F., and F. D. Ledley. 1989. Primary sequences homology between methylmalonyl Coa mutase from Propionibacterium shermanii and Homo sapiens. Cobalamin '88. Proc. Int. Symp. Biomed. Physiol. Vitamin B12, Ist, London. 343-354.

33. Marsh, N., P. F. Leadlay, and P. R. Evans. 1988. Crystallization and preliminary diffraction data for adenosylcobalamin-dependent methylmalonylCoA mutase from Propionibacterium shermanii. J. Mol. Biol. 200:421-422. 